Pacific Northwest

National Laboratory

Operated by Battelle for the

U.S. Department of Energy

\title{
Composite Signatures of Nuclear and Non-Nuclear Technologies for Weapons Material and Component Measurement
}

\author{
R. Kouzes \\ B. Geelhood
}

April 2002

Prepared for the U.S. Department of Energy under Contract DE-AC06-76RL01830 


\title{
DISCLAIMER
}

This report was prepared as an account of work sponsored by an agency of the United States Government. Neither the United States Government nor any agency thereof, nor Battelle Memorial Institute, nor any of their employees, makes any warranty, express or implied, or assumes any legal liability or responsibility for the accuracy, completeness, or usefulness of any information, apparatus, product, or process disclosed, or represents that its use would not infringe privately owned rights. Reference herein to any specific commercial product, process, or service by trade name, trademark, manufacturer, or otherwise does not necessarily constitute or imply its endorsement, recommendation, or favoring by the United States Government or any agency thereof, or Battelle Memorial Institute. The views and opinions of authors expressed herein do not necessarily state or reflect those of the United States Government or any agency thereof.

\author{
PACIFIC NORTHWEST NATIONAL LABORATORY \\ operated by \\ BATTELLE \\ for the \\ UNITED STATES DEPARTMENT OF ENERGY \\ under Contract DE-AC06-76RL01830
}

Printed in the United States of America

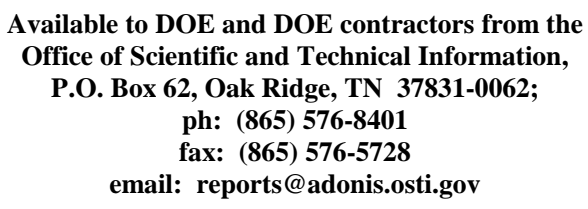

Available to the public from the National Technical Information Service, U.S. Department of Commerce, 5285 Port Royal Rd., Springfield, VA 22161 ph: (800) 553-6847 fax: $(703) 605-6900$

email: orders@ntis.fedworld.gov

online ordering: http://www.ntis.gov/ordering.htm 


\title{
Composite Signatures of Nuclear and Non-Nuclear Technologies for Weapons Material and Component Measurement
}

\author{
R. Kouzes \\ B. Geelhood
}

January 2001

Revised April 2002

Prepared for

The U.S. Department of Energy

under Contract DE-AC06-76RLO 1830

Pacific Northwest National Laboratory

Richland, Washington 99352 


\title{
Composite Signatures of Nuclear and Non-Nuclear Technologies for Weap- ons Material and Component Measurement
}

\begin{abstract}
Summary
Attribute measurement systems are being developed in support of arms-reduction negotiations to verify compliance with the disassembly of nuclear weapons and disposition of material. The currently demonstrated attribute measurement systems utilize nuclear radiation detection technologies. Alternative low-intrusion non-nuclear measurement techniques may offer access to relevant information, e.g. mass of an item, when combined with information from a nuclear radiation measurement. This document examines the application of low-intrusion nonnuclear methods in combination with nuclear methods for attribute measurement systems. Several specific combinations are evaluated.
\end{abstract}




\section{Acronyms}

AMS/IB Attribute Measurement System with Information Barrier

CTR Cooperative Threat Reduction

DTRA Defense Threat Reduction Agency

DU Depleted uranium - uranium that is the residual by-product of the enrichment process

EM Electro-magnetic

FMSF Fissile Material Storage Facility - facility to store fissile materials from dismantled nuclear weapons being built in Russia at Mayak by the US government

FMTT Fissile Material Transparency Technology

FMTT-AMS Fissile Material Transparency Technology-Attribute Measurement System - a radiation measurement system developed by Los Alamos National Laboratory and Livermore National Laboratory, demonstrated to the Russian Federation in August 2000

HEU Highly Enriched Uranium

HPGe High-Purity Germanium - a high-resolution gamma-ray detector

MME Minimum Mass Estimate - analysis software developed at Sandia National Laboratory using gamma-ray attenuation to estimate the minimum plutonium mass

NMC Neutron Multiplicity Counter - a coincident neutron measurement system developed by Los Alamos National Laboratory

NMIS Nuclear Materials Inspection System - a radiation measurement system developed by Oak Ridge National Laboratory

NMR Nuclear Magnetic Resonance

TRADS Trusted Radiation Attribute Demonstration System - a radiation measurement system developed by Sandia National Laboratory using a HPGe sensor 


\section{Contents}

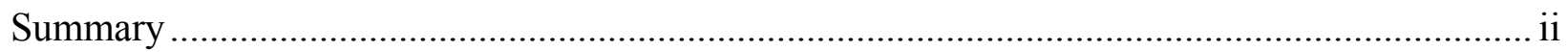

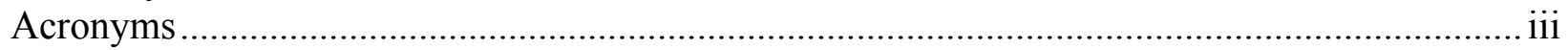

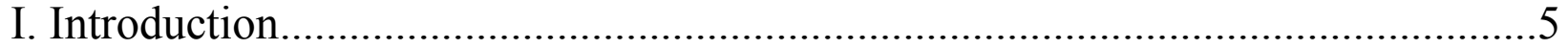

II. Attribute Measurement and Template Systems ............................................6

III. Non-Nuclear Low-Intrusion Measurement Methods.......................................

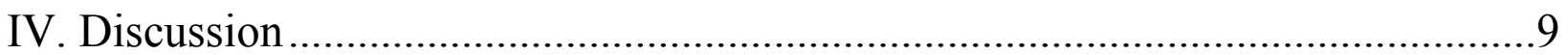

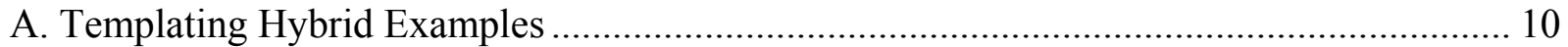

B. Attribute Measurement Hybrid System Examples.............................................................. 12

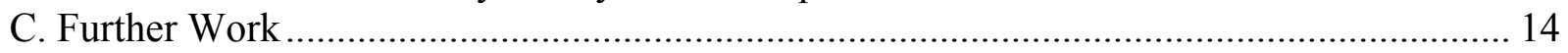

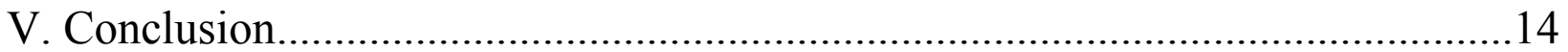

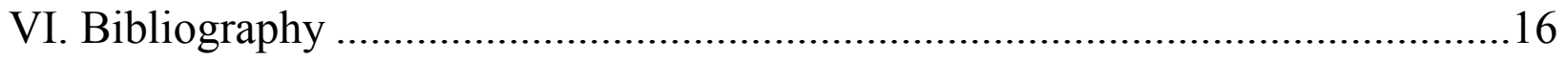

Appendix A. Nuclear Radiation Measurement Techniques ...................................18

Appendix B. Non-Nuclear Measurement Methods ...............................................21

A. EM Coil Impedance or Other Electromagnetic Property ............................................. 21

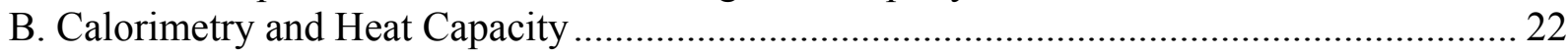

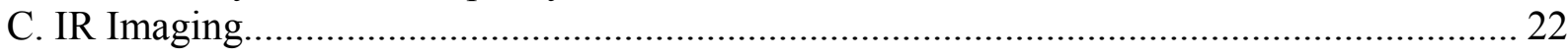

D. Weight Measurement or Density Determination ................................................................ 23

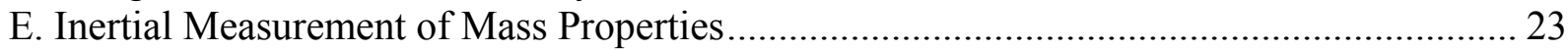

F. Acoustic or Mechanical Resonance or Imaging ............................................................... 24

G. Chemical Sensing, Gas Chromatography, and Mass Spectrometry ………………............ 25

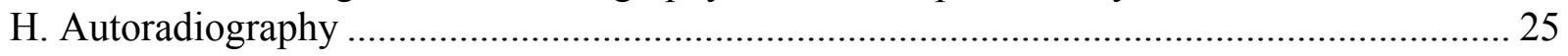

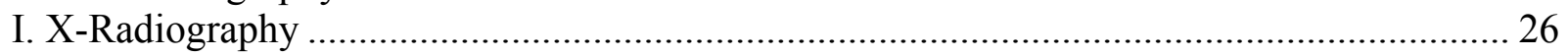

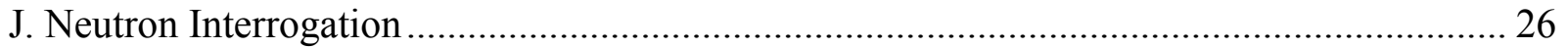

Appendix C. Comparison of Nuclear and Non-Nuclear Measurement Methods....28 Appendix D. Some Properties of Plutonium ...........................................................35 


\section{Composite Signatures of Nuclear and Non-Nuclear Technologies for Weapons Material and Component Measurement}

\section{Introduction}

Various attribute measurement systems with information barriers (AMS/IB) are being developed in support of the US government's needs related to arms control. At this time the major focus is the Defense Threat Reduction Agency's (DTRA's) program for the Mayak Fissile Material Storage Facility (FMSF). DTRA and the US Department of Energy (DOE) have ongoing alternate technology development programs at the Pacific Northwest National Laboratory (PNNL) and elsewhere.

This document discusses composite signatures using low-intrusion, non-nuclear technologies in conjunction with passive nuclear radiation detection methods available for attribute or template measurements. This document does not evaluate the individual low-intrusion technologies as has already been done by the Alternative Technologies Working Group, ${ }^{1}$ but considers how they might complement nuclear radiation measurement approaches. This is a follow-on to a document that examined alternative radiation measurement techniques. ${ }^{2}$

Disarmament agreements have requirements for detection of current and former weapons material, including plutonium, uranium, and high explosives. There are neutron and gamma-ray counting technologies currently being used for detection of these materials based upon "attributes." Attributes are measurable properties of items that are characteristic of weapons material and collectively provide confidence in the presence of such material. Material-based attributes apply to arms-control applications relating to full-up weapons, weapon components, and material residuals following dismantlement.

The terms "alternative technologies" and "low-intrusion technologies" have been applied to non-nuclear detection methods for determining attributes of weapons-origin material. These methods include calorimetry, electromagnetic methods, mechanical methods, radiography, infrared imaging, etc. The radiation detection technologies proposed have generally been limited to passive radiation techniques. As used here, alternate technologies includes some active radiation techniques (e.g., X-ray imaging and neutron interrogation), but only in the context of examination of empty or non-sensitive container verification. Passive nuclear techniques for attribute measurement involve gamma-ray and neutron detection, as summarized in Appendix A.

Alternate attributes to the nuclear radiation attributes, such as persistent heat output, complex impedance, or shape as determined by autoradiography, can be used in an arms control regime either singly or in hybrid attribute measurement systems along with nuclear techniques. Such hybrid systems produce "composite signatures" that might be motivated by a need to be less intrusive of classified information, or for observing modifications to material over time, such as oxidation of a metal. A standard Calorimetry measurement is a good example of a hybrid

\footnotetext{
${ }^{1}$ ATWG Preliminary Report 1999

${ }^{2}$ PNNL-13250, R. Kouzes and B. Geelhood 2000
} 
system because it uses both a gamma-ray measurement to determine the plutonium isotopic ratios and a heat output measurement to determine the plutonium sample mass. A further advantage of some methods is that the sensors used are each relatively simple and low cost, allowing an expansion of inventory measurements to longer times or more samples. For example, in the Plutonium Finishing Plant at Hanford, individual cans of $\mathrm{PuO}_{2}$ are instrumented with sensitive thermometers.

\section{Attribute Measurement and Template Systems}

An attribute-based measurement system uses measured information plus physics based analysis to produce characteristic parameter values and makes a decision about the type of observed material based on the parameter values falling within a previously agreed range of values. "Templating" is an alternative to attribute measurements. A template-based measurement system stores raw measured information characteristic of an individual item, or a class of items, for later comparison to that item or similar items. In some templating schemes, classified information is stored, which may be problematic and has resulted in less programmatic development of the templating approach. Some non-nuclear technologies (e.g., electromagnetic, acoustic, or inertial signatures) may also be well suited to templating since they can use lower sensitivity, potentially unclassified data to show whether an item is similar or not to a standard set of items. Template information used in some radiation measurement schemes is classified, because similar information has been previously used to extract weapon design information.

An attribute measurement system ideally determines the desired material attributes unequivocally and provides a Yes/No output through an information barrier that protects any classified information. Existing AMS/IB systems usually consist of gamma-ray and neutron detectors. Non-nuclear attribute measurement methods may be used to supplement or replace nuclear methods. For example, calorimetry, the long-used process of measuring heat production of a sample, can make a very good determination of plutonium mass if the isotopic composition of a sample is known from a high-resolution gamma-ray measurement. AMS systems utilize an information barrier to protect classified information. Some low-intrusion technologies have an advantage over radiation technologies of inherently providing an information barrier.

The key question for arms control applications is the optimal choice of technologies for an attribute measurement system or templating system that provides a reasonable trade off of:

- cost of the complete system

- effectiveness of attribute or template determination

- time duration required for measurement

- flexibility of measurement

- robustness of the measurement

- protection of classified information

- confidence in the validity of the result (transparency and authentication)

- time to implement and certify for use in monitoring applications. 


\section{Non-Nuclear Low-Intrusion Measurement Methods}

Table 1 provides a summary of most non-nuclear low-intrusion attribute measurement methods that can potentially be used in arms control applications.

Table 1: Non-Nuclear Attribute Measurement Methods of Interest to Arms Control.

\begin{tabular}{|c|c|}
\hline Alternate Technology & Description \\
\hline $\begin{array}{l}\text { EM-Coil impedance or } \\
\text { other electromagnetic } \\
\text { property }\end{array}$ & $\begin{array}{l}\text { An electromagnetic (EM) coil complex impedance measure- } \\
\text { ment can differentiate between materials (e.g., metal from ox- } \\
\text { ide). }\end{array}$ \\
\hline $\begin{array}{l}\text { - Calorimetry and heat ca- } \\
\text { pacity }\end{array}$ & $\begin{array}{l}\text { The measurement of the power output of a sample produced } \\
\text { from radioactive decay. Given the isotopic composition, the } \\
\text { power output provides an accurate measurement of mass. The } \\
\text { measurement of the heat capacity of a sample can potentially } \\
\text { differentiate materials, especially metal from non-metal. A } \\
\text { developed technology currently used to monitor plutonium. }\end{array}$ \\
\hline - IR imaging & $\begin{array}{l}\text { Infrared imaging measurements provide an accurate tempera- } \\
\text { ture profile of the exterior of a container. Linked to knowledge } \\
\text { of convective, conductive, and radiative heat transfer, IR imag- } \\
\text { ing can provide a persistent power output measurement that is } \\
\text { linked to mass. }\end{array}$ \\
\hline $\begin{array}{l}\text { - Weight measurement or } \\
\text { density determination }\end{array}$ & $\begin{array}{l}\text { Weighing can place a limit on the contents of a container and } \\
\text { can provide an accurate comparison over time. Special nuclear } \\
\text { materials have high density, so a density determination can } \\
\text { differentiate between heavy metals, light metals, and oxide. }\end{array}$ \\
\hline $\begin{array}{l}\text { - Inertial measurement of } \\
\text { mass properties }\end{array}$ & $\begin{array}{l}\text { The moments of inertia can determine symmetry, density and } \\
\text { mass, and shape constraints on a sample. }\end{array}$ \\
\hline $\begin{array}{l}\text { - Acoustic mechanical reso- } \\
\text { nance or imaging }\end{array}$ & $\begin{array}{l}\text { Mechanical resonance, produced by shaking, acoustics, or hit- } \\
\text { ting, can potentially provide a template for a sample. }\end{array}$ \\
\hline $\begin{array}{l}\text { - Chemical sensing, gas } \\
\text { chromatography, mass } \\
\text { spectrometry }\end{array}$ & $\begin{array}{l}\text { Sensitive chemical detection methodologies can potentially } \\
\text { determine the presence of specific elements or compounds. }\end{array}$ \\
\hline - Autoradiography & $\begin{array}{l}\text { Autoradiography is an image of an object produced by the } \\
\text { radiation emission of a sample. A passive form of radiography } \\
\text { without an external X-ray source. }\end{array}$ \\
\hline $\begin{array}{l}\text { - X-radiography (X-ray } \\
\text { image) }\end{array}$ & $\begin{array}{l}\text { X-rays passing through a sample can produce an image propor- } \\
\text { tional to the density of the enclosed material. }\end{array}$ \\
\hline - Neutron interrogation $^{4}$ & $\begin{array}{l}\text { A neutron source is used to induce activity in a sample through } \\
\text { induced fission, excitation, or absorption, or for elastic scatter- }\end{array}$ \\
\hline
\end{tabular}

\footnotetext{
${ }^{3} \mathrm{X}$-radiography is intrusive and only considered here for empty or non-sensitive container verification.

${ }^{4}$ Neutron interrogation is normally considered a nuclear technique. It is included here for completeness since it has been considered in the context of alternative technologies. This technique is intrusive and is only considered for empty or non-sensitive container verification.
} 
ing.

The methods listed above have been developed to varying degrees for application to arms control at a number of laboratories. ${ }^{5}$ Appendix B provides a summary explanation of these various non-nuclear low-intrusion methods. Tables 3 through 7 in Appendix C provide a summary of material attributes of interest to arms control and the possible nuclear and non-nuclear methods for measurement of those attributes. The tables include attributes for plutonium (Tables 3-4), uranium (Tables 5), other fissionable materials (Table 6), and high explosives (Table 7).

\section{Discussion}

The requirements for an attribute or templating measurement system depend upon where it is used in an arms-reduction lifecycle. Measurements on full-up weapons have the highest level of security concern for the host, while end-of-lifecycle materials (e.g., oxide) will usually be of less concern. Templating may be most useful in some application arenas, while attribute measurements may be required in others. Low-intrusion, non-nuclear measurement methods can be implemented as part of either attribute measurement systems or templating systems. These measurement methods can play a role in a number of lifecycle scenarios.

The attribute of plutonium isotopics does not lend itself to non-nuclear low-intrusion technologies. Intrusive non-nuclear methods such as mass spectroscopy are possible. Measurement of specific gamma-ray peaks associated with the various plutonium isotopes is necessary to measure plutonium isotopics in a non-destructive and non-invasive manner. The following Table 2 addresses what various non-nuclear measurement methods can add to a basic highresolution gamma spectroscopy measurement. The plutonium isotopics attribute may not be necessary for every application. Note that a template approach or count-against-a-standard approach may not require plutonium isotopics to address mass at some level. Thus, the table also addresses what various non-nuclear measurement systems can add to a basic gross neutron count.

Low-intrusion, non-nuclear attribute measurement techniques for weapons reduction purposes have a variety of applications and some are mature enough to consider in implementation planning. Some methods have the significant advantage of a short measurement time. We will only consider two-component hybrid measurement systems. Table 2 provides some examples of hybrid systems that use a non-nuclear low-intrusion attribute measurement or templating technique along with a radiation measurement method. These low-intrusion hybrid methods are probably most useful in two areas of application:

- In templating applications such as a comparison of measurements over time to look for physical changes such as oxidation or to validate the lack of tampering.

- In hybrid attribute or templating systems to reduce the intrusiveness of a measurement.

\footnotetext{
${ }^{5}$ ATWG Preliminary Report 1999
} 
Table 2: Example Possible Uses of Two-Component Hybrid Systems Involving NonNuclear Low-Intrusion Attribute Measurement Methods Combined with Radiation Measurements of Interest to Arms Control.

\begin{tabular}{|c|c|c|}
\hline Alternate Technology & \begin{tabular}{||c|} 
Gamma-Ray Measurement \\
For plutonium presence and \\
isotopic composition of pluto- \\
nium plus:
\end{tabular} & \begin{tabular}{|c|} 
Passive Neutron Measure- \\
ment \\
For presence of spontaneously \\
fissionable material plus:
\end{tabular} \\
\hline $\begin{array}{l}\text { EM-Coil impedance or other } \\
\text { electromagnetic property }\end{array}$ & $\begin{array}{l}\text { Template or attribute system } \\
\text { for metal versus oxide form; } \\
\text { template system for geometry }\end{array}$ & $\begin{array}{l}\text { Template or attribute system } \\
\text { for metal versus oxide form; } \\
\text { template system for geometry }\end{array}$ \\
\hline $\begin{array}{ll}\text { - } & \text { Calorimetry and heat capac- } \\
\text { ity }\end{array}$ & $\begin{array}{l}\text { Template or attribute system } \\
\text { for plutonium mass }\end{array}$ & $\begin{array}{l}\text { Template system for plutonium } \\
\text { mass }\end{array}$ \\
\hline - IR imaging & $\begin{array}{l}\text { Template or attribute system } \\
\text { for rough plutonium mass }\end{array}$ & $\begin{array}{l}\text { Template system for rough } \\
\text { plutonium mass }\end{array}$ \\
\hline $\begin{array}{l}\text { - } \begin{array}{l}\text { Weight measurement or } \\
\text { density determination }\end{array} \\
\end{array}$ & $\begin{array}{l}\text { Template or attribute system } \\
\text { for rough mass }\end{array}$ & $\begin{array}{l}\text { Template or attribute system } \\
\text { for rough mass }\end{array}$ \\
\hline $\begin{array}{l}\text { - Inertial measurement of } \\
\text { mass properties }\end{array}$ & $\begin{array}{l}\text { Template system for shape, } \\
\text { mass, density, and form }\end{array}$ & $\begin{array}{l}\text { Template system for shape, } \\
\text { mass, density, and form }\end{array}$ \\
\hline $\begin{array}{l}\text { Acoustic mechanical reso- } \\
\text { nance or imaging }\end{array}$ & $\begin{array}{l}\text { Template system for shape, } \\
\text { density, and form }\end{array}$ & $\begin{array}{l}\text { Template system for shape, } \\
\text { density, and form }\end{array}$ \\
\hline $\begin{array}{l}\text { Chemical sensing, gas chro- } \\
\text { matography, mass spec- } \\
\text { trometry }\end{array}$ & $\begin{array}{l}\text { Template or attribute system } \\
\text { for chemical composition }\end{array}$ & $\begin{array}{l}\text { Template or attribute system } \\
\text { for chemical composition }\end{array}$ \\
\hline - Autoradiography & $\begin{array}{l}\text { Template system for rough } \\
\text { minimum plutonium mass or } \\
\text { shape }\end{array}$ & $\begin{array}{l}\text { Template system for rough } \\
\text { minimum plutonium mass or } \\
\text { shape }\end{array}$ \\
\hline $\begin{array}{ll} & \begin{array}{l}\text { X-radiography (X-ray im- } \\
\text { age })^{6}\end{array}\end{array}$ & Template system for shape & Template system for shape \\
\hline - $\quad$ Neutron interrogation $^{7}$ & $\begin{array}{l}\text { Template or attribute system } \\
\text { for presence of HEU or HE }\end{array}$ & $\begin{array}{l}\text { Template or attribute system } \\
\text { for presence of HEU or HE }\end{array}$ \\
\hline
\end{tabular}

\section{A. Templating Hybrid Examples}

Low-intrusion, non-nuclear attribute-measurement techniques are well suited to providing a record over time of the properties of an individual item. This is a form of templating where a measurement history of a single item, or a class of items, is periodically monitored to look for

\footnotetext{
${ }^{6} \mathrm{X}$-radiography is intrusive and is only considered here for empty or non-sensitive container verification.

${ }^{7}$ Neutron interrogation is normally considered a nuclear technique. It is included here for completeness since it has been considered in the context of alternative technologies. It is intrusive and is only considered for empty or non-sensitive container verification.
} 
changes that might be indicative of safety or tampering concerns. The following are a few examples of templating applications of hybrid systems.

\section{EM-Coil Template Usage for Class Characterization}

The EM-coil impedance technique can be used to distinguish a class of items that show similar response. Assume that a gamma-ray radiation measurement has indicated the presence of plutonium or HEU. An example application of the EM-coil impedance technique would then be to distinguish spheres of material from cylinders of material inside a container. This type of measurement probably allows for an unclassified templating method that provides a level of confidence that a set of containers enclose similar contents. This class of containers can be compared over time to validate the lack of tampering or degradation that would signify a safety concern. The use of an EM-coil template specific to a declared class of canisters does not avoid canister variation problems, but utilizes the sensitivity to sample shape and orientation.

\section{EM-Coil Template Usage for Material Safety or an Oxide Attribute}

Oxidation of plutonium metal is a safety concern that can occur slowly over many years. Assuming a gamma-ray radiation measurement has indicated the presence of plutonium, a periodic EM-coil measurement of a metal item using electromagnetic impedance can provide assurance that an item is unchanged in time. Such information cannot be extracted from radiation measurements or calorimetry. This periodic measurement compared over time could validate the lack of tampering or degradation that would signify a safety concern. The use of an EM-coil template specific to identified canisters avoids canister variation problems and utilizes the potential sensitivity to small amounts of oxidation. The EM-coil can easily distinguish a metal geometry from a similar geometry of an oxide, thus allowing for the measurement of this metal/oxide attribute.

\section{Inertial Measurement Usage for Shape}

Assuming a gamma-ray radiation measurement has indicated the presence of plutonium or HEU, an inertial measurement might provide a template for the configuration of the contents of a container. This method is limited to metal or other solid items since powders might shift under motion and thus change shape. A periodic measurement compared over time could validate the lack of tampering with the contents.

\section{Acoustic Measurement Usage for Shape}

Assuming a radiation measurement has indicated the presence of plutonium or HEU, an acoustic template recording can be made that is a template related to the configuration of the contents of a container. A periodic measurement compared over time could validate the lack of tampering with the contents. 


\section{Non-Spectroscopic Determination of Plutonium Isotopics}

The isotopic composition of plutonium is required for several measurement techniques related to the plutonium mass. The plutonium isotopics are generally measured with a highresolution gamma-ray spectrometer if a non-invasive scheme is required. Alternately, the plutonium could be invasively sampled for a mass spectrometer. The plutonium isotopics are required for several measurements because each isotope has a unique contribution to several observables - spontaneous fission rate, induced fission neutrons, or heat produced by alpha decay. The set of values corresponding to these observables forms a template for a particular set of isotopics. This could provide a non-spectroscopic template of isotopics. This is useful if high-resolution gammaray spectrometry is disallowed, but plutonium isotopics is desired to prove weapon-grade plutonium.

\section{B. Attribute Measurement Hybrid System Examples}

Attribute measurement systems determine a definable property of an item. For example, calorimetry can be used to accurately determine the important attribute of absolute mass of an item independent of form or geometry, and more recent techniques, such as IR imaging, may be able to provide a less accurate measurement of this mass attribute. These mass measurements require knowledge of the isotopic ratio of a plutonium item, which must typically be made with a high-resolution gamma-ray detector.

Hybrid attribute systems that consist of a nuclear technique plus an alternate lowintrusion technique may be more acceptable to a host for certain application scenarios, may be more time or cost effective, or may be more applicable to use in the field. Measurement equipment must often be used in field portable or harsh environments where robustness of equipment and portability are concerns. Some low-intrusion, non-nuclear technology approaches may be more effective under such constraints. The following are a few examples of attribute measurement applications of hybrid systems.

\section{Calorimetry Usage for Plutonium Mass}

Assuming the isotopic composition of a plutonium item has been measured, a calorimetric measurement can accurately determine the mass of plutonium. The major limitation of this technique is a few hours time typically required for system equilibrium, which reduces the throughput. This type of measurement is used for material management today. Periodic measurements compared over time could validate the integrity of an item. Calorimetry is an alternative to a neutron multiplicity counter. Two advantages are lower initial cost and transparency of the analysis. Both calorimetry and a neutron multiplicity counter require a large fixed measurement chamber and an independent measure of plutonium isotopics. A disadvantage of calorimetry is the longer measurement time. With no measurement of isotopics, a template can still be made which is characteristic of the material measured. 


\section{IR Imaging Usage for Plutonium Mass}

Assuming a measurement of the isotopic composition of a plutonium item, an infrared imaging measurement potentially could determine the approximate mass of a plutonium item under controlled circumstances where modeling can predict the heat transport away from a container. The time for such a measurement is significantly less than calorimetry, with a tradeoff on mass precision. Periodic template measurements compared over time could validate the integrity of an item. For approximate mass, IR imaging is potentially an alternative to a neutron multiplicity counter. Advantages include lower initial cost, transparency of the analysis, rapid measurements, and potential for in situ measurements.

\section{Autoradiography Usage for Plutonium Mass}

Assuming a measurement has been made of the isotopic composition of a plutonium item, an autoradiograph could potentially set a minimum mass level for a known geometry. Minimum mass is measured rather than actual mass since only the radiation from the outer material of an item is not self-attenuated or attenuated in the packing material. Autoradiography is more useful for shape or geometric parameter determination. The shape and mass can often be converted into a density indicative of the chemical form of the plutonium. Periodic template measurements compared over time could validate the integrity of an item.

\section{Weight Measurement Usage for Plutonium Mass}

Assuming a radiation measurement has determined the presence of plutonium or HEU, a gross weight measurement can be used as a characteristic of a particular item. Since the mass of the container and packing is often much larger than the item mass, and shows variation from container to container, weight does not provide much information other than a limit about the mass of the plutonium or HEU item. Periodic template-like measurements compared over time could validate the lack of tampering with a specific container.

\section{Inertial/Weight Measurement Usage for Plutonium Mass and Density}

This scheme would measure three independent moments of inertia and the total mass. The analysis would remove uncertainty in the canister mass and yield a density and net weight for the plutonium sample. The analysis requires information regarding the canister. The mass would not necessarily be specific to plutonium. However, gamma-ray and singles neutron counts could be used for consistency checks. The advantages of a moment of inertia scheme are that it could avoid a complex system, could be fully transparent, could potentially be cheaper, and could require a shorter measurement time.

\section{Neutron Interrogation Usage for Presence of High Explosives}

Assuming a radiation measurement has determined the presence of plutonium or HEU, a neutron interrogation method can potentially indicate the presence of high explosive in a weapon configuration. Techniques use either time tagged neutrons to measure elastic scattering or fast neutron excitation gamma rays such as from nitrogen. 
The presence of hydrogenous moderating material can be rapidly determined by a scheme that measures the time-to-detection of time-tagged neutrons. A very low intensity neutron source is used. Although detection of hydrogen is not uniquely indicative of high explosives (HE) because of many alternative sources of hydrogen, there are times when rapid detection of hydrogen is valuable. In a full-up weapon, hydrogen detection can indicate that the HE has not yet been removed. After disassembly, lack of hydrogen in a waste container indicates the HE is not in the container. The primary value of this technique is the rapid response, which is much faster than the time required to acquire a $2223-\mathrm{keV}$ hydrogen-capture peak in a gamma-ray spectrum. The instrumentation is also light weight and hand portable. This alternate approach is highly promising to fill the need for rapid high-explosives detection in some scenarios. Its value might be increased by a more unique HE identification at another stage of weapon dismantlement.

\section{Further Work}

Further work is needed to demonstrate the value of hybrid attribute or templating systems. A few demonstration projects should be funded to show scenarios for the use of hybrid systems combining nuclear and low-intrusion techniques.

Nuclear radiation measurement techniques are well established, but are sometimes perceived as too intrusive because they can reveal classified information about a material. Lowintrusion non-nuclear technique demonstrations should exploit their potential for providing an inherent information barrier preventing the release of classified information. Demonstrations should also show the potential for portable systems for field applications.

A possible project could demonstrate IR imaging, EM-coil impedance, and gamma-ray instrumentation together for measurements on unclassified items. Such a measurement system could demonstrate the inherent information barrier provided by the low-intrusion technologies. Such a system could be of value for materials safety in an unclassified setting such as oxide storage for the Plutonium Production Reactor Agreement (PPRA) or for metal storage at Mayak.

\section{Conclusion}

A variety of non-nuclear low-intrusion technologies exist that can contribute to the measurement of attributes for weapons origin material. These techniques generally require some information from nuclear measurement techniques such as isotopic ratio, but once such information is established, alternate technologies can provide valuable information about a sample.

Electromagnetic impedance measurement techniques show great promise for templating and for observing the deterioration of a sample such as oxidation of plutonium. Imaging methods are very useful for shape determination. Mechanical measurements can place limits on material properties. Calorimetry is routinely used for accurate determination of material mass, but has a limitation due to the long measurement time required. Low-intrusion, non-nuclear technologies thus have the potential to play a significant role in the weapons attribute measurement arena. 
Further development of low-intrusion, non-nuclear attribute measurement methods is required. Higher visibility of the capabilities of these methods is needed. Demonstration hybrid systems combining low-intrusion non-nuclear technologies with radiation measurements should be developed. 


\section{Bibliography}

ATWG, "Preliminary Report on Alternate Technologies in Support of Start III Transparency", Joint DOE/DoD Integrated Technology Steering Committee Alternate Technology Working Group, September 3, 1999

Batishko, C., “Thermal Infrared Signatures”, optiker.crb@pnl.gov

Caffrey, A.J., J.D. Cole, R.J. Gehrke, and R.C. Greenwood, "Chemical Warfare Agent and High Explosive Identification by Spectroscopy of Neutron-Induced Gamma Rays," IEEE Transactions on Nuclear Science 39, p. 1422-1426 (1992).

Caffrey, A.J., R.J. Gehrke, R.C. Greenwood, J.K. Hartwell, K.M. Krebs, G.D. McLaughlin, A.L. Siedenstrang, and K.D. Watts, "U.S. Army Experience with the PINS Chemical Assay System," Idaho National Engineering Laboratory report EGG-NRP-1143 (1994)

Beddingfield, D. H. and F. E. Cecil, "Identification of Fissile Materials from Fission Product Gamma-Ray Spectra", Nuclear Instruments and Methods in Physics Research, Section A, 417:405-412 (1998).

Craig, R.A., A. J. Peurrung, and D. C. Stromswold, "Mine Detection Using Timed Neutron Moderation", conference proceedings of the UXO/Countermine Forum, May 2000.

Hockey, R., "Electromagnetic Coil Technique for Arms Control Applications", INMM Conference Record, Indian Wells, CA, July 2001, ronald.hockey@pnl.gov

Kouzes, R., and B. Geelhood, "Methods for Attribute Measurement and Alternatives to Multiplicity Counting", PNNL-13250, May 17, 2000

Krautkramer, J. and H. Krautkramer, Ultrasonic Testing of Materials, $4^{\text {th, }}$, fully revised edition, Springer-Verlag, New York 1990.

LANL, "Results of Preliminary Evaluations of Alternative Methods of Nuclear Weapon Component Identification", September 1993)

Mihalczo, J. T., V. K. Pare, E. D. Blakeman, B. Damiano, T. E. Valentine, L. D. Phillips, "NWIS Signatures for Confirmatory Measurements with B33 Trainers," Journal of Institute of Nuclear Materials Management, 1997.

Mihalczo, J. T. and T. E. Valentine, "Nuclear Weapons Identification System," submitted to Arms Control and Nuclear Technologies, 1997. 
Miller, S., "Use of Optically Stimulated Luminescence Imaging Plates and Readers for Arms Control Applications", INMM Conference Record, Indian Wells, CA, July 2001, steven.miller@pnl.gov

PANDA: Reilly, D., N. Ensslin, H. Smith, Jr., and S. Kreiner, editors, Passive Nondestructive Assay of Nuclear Materials, ISBN 0-16-032724-5, U.S. Government Printing Office, Washington, D.C. 1991.

Peurrung, A., et al. 2000, "The 871-keV Gamma Ray From Oxygen-17 And

The Misidentification Of Plutonium Oxide”, PNNL-SA-33134, May 2000

Romero, R., Application Guide to Neutron Multiplicity Counting, Los Alamos National Laboratory, 1998.

Valentine, T. E., L. G. Chiang, and J. T. Mihalczo, "NMIS for Interrogation of Pu and HEU in AT400-R Containers at Mayak," ORNL/M-6648, R1, Oak Ridge National Laboratory, March 1999.

Wick, O.J., editor, Plutonium Handbook, A Guide to the Technology, Volume I \& II, Gordon and Breach, Science Publishers, New York, 1967. 


\section{Appendix A. Nuclear Radiation Measurement Techniques}

Gamma-ray and neutron measurements are extensively used to identify the presence of fissionable material and its daughters.

Most gamma rays originate in weapons material from plutonium and americium isotopes. Only gamma-ray measurements using high-resolution, high-purity germanium (HPGe) detectors (that have a resolution of a few $\mathrm{keV}$ in the energy region of interest) can determine the isotopic ratio of ${ }^{240} \mathrm{Pu} /{ }^{239} \mathrm{Pu}$, which is about $6 \%$ for weapons grade material. HPGe measurements can also determine the mass of plutonium in the outer volume of a sample ("minimum mass"). Since plutonium is highly self-attenuating to gamma rays, and thus the gamma rays from the interior of a thick source are not seen due to self-attenuation, HPGe measurements are limited to this minimum-mass determination, which can provide evidence of a hollow sphere being up to about $20 \%$ of the potential mass of a solid sphere. Gamma-ray measurements can also imply the age of a sample by determining the amount of in-growth americium, as well as the symmetry of a sample.

Neutrons arise from spontaneous and induced fission, and from $(\alpha, n)$ reactions on light elements in or around the alpha emitting element (e.g., plutonium and daughters such as americium). Each fission process on average produces multiple neutrons per event. A single ${ }^{240} \mathrm{Pu}$ spontaneous fission produces 0 to 6 neutrons, with $\left\langle v\left({ }^{240} \mathrm{Pu}\right)\right\rangle=2.16$ (PANDA p. 342). A single induced fission in ${ }^{239} \mathrm{Pu}$ produces a slightly higher number of neutrons, with $\left\langle v\left({ }^{239} \mathrm{Pu}\right)\right\rangle=2.88$ (PANDA p. 342). Neutrons produced by $(\alpha, n)$ reactions on light elements are produced individually, with $\langle v(\alpha, n)\rangle=1$. The energy distributions of fission neutrons and $(\alpha, n)$ neutrons are very different. Compared to the fission spectrum, the $(\alpha, n)$ reaction produces higher energy neutrons in materials such as beryllium, carbon, and oxygen and lower energy neutrons in lithium.

Neutrons can induce fission events in fissile material and $(n, 2 n)$ reactions, which give rise to a third neutron parameter, the multiplication factor. The total multiplication factor, $\mathrm{M}_{\mathrm{T}}$, is the ratio of the total number of sample neutrons to the non-induced fission neutrons [spontaneous fission, $(\alpha, n)$ neutrons, ...]. $\mathrm{M}_{\mathrm{T}}$ is related to the effective criticality factor value $\left(\mathrm{k}_{\mathrm{eff}}\right)$ by $\mathrm{M}_{\mathrm{T}}=$ $1 /\left(1-\mathrm{k}_{\mathrm{eff}}\right)$. The multiplication value reported by a Neutron Multiplicity Counter (NMC) analysis, $\mathrm{M}$, is the leakage multiplication, which is reduced by the small probability of neutron capture in the sample without induced fission, $\mathrm{p}$, or $\mathrm{M}=(1-\mathrm{p}) * \mathrm{M}_{\mathrm{T}}$. Weapons components are designed with low $\mathrm{k}_{\text {eff }}$ to facilitate storage, which implies that the multiplication factor is small for weaponsorigin material when in a weapon configuration. The effect of multiplication increases with increasing sample mass (PANDA 1991 p. 425) and the average distance through the fissile material that emitted neutrons travel. Multiplication can be calculated as a function of mass and sample configuration. A plutonium mass of 500-grams is the unclassified threshold mass established for weapon's origin material. For a near 500-gram mass, the total neutron count rate increases by about 5\% due to multiplication, which would increase the neutron coincidence response by about $28 \%$ if the electronics are not adjusted to reject multiple pairs from coincident bursts (PANDA $p$ 478-483). Thus, at the threshold mass of 500-grams, the maximum overestimate of the mass would be about $28 \%$ for a coincidence technique and $5 \%$ for a singles neutron counter, and would likely be much less in practice. 
Neutron measurements can measure the total flux (singles) or neutron coincidence events (doubles, triples, or higher multiplicity). Neutron singles measurements only determine the total flux of neutrons, which is a combination of $(\alpha, n)$ reaction neutrons and fission neutrons. If it is known that the source composition is metallic without low- $Z$ contamination, the $(\alpha, n)$ component can be negligible, and singles can provide an adequate measure of the plutonium mass when combined with a consistent estimate of the multiplication. Neutron doubles measurements find the singles rate and the pairs coincidence rate, which allows a determination of the fission rate (and thus plutonium mass) and the $(\alpha, n)$ flux. A doubles measurement can also independently measure the mass and multiplication when the $(\alpha, n)$ flux is known to be zero due to knowledge of the materials or independent gamma-ray measurements. The efficiency of the neutron counters must be greater than about $1 \%$ for the determination of the doubles rate. Neutron triples measurements find the singles neutron flux, the double coincidence rate, and the triple coincidence rate, which allows a measure of the fission rate (and thus plutonium mass), the ( $\alpha, n)$ flux, and the multiplication. Neutron Multiplicity Counters can detect even higher orders of coincident neutrons. Multiplication in the source can produce large numbers of additional neutrons through induced chain-reactions. Thus, up to 20 coincident neutrons can be observed from large plutonium sources with a neutron detection efficiency of 56\% (Romeo 1998) in a neutron multiplicity counter.

Radiation based attribute measurements are currently being demonstrated for armscontrol applications. Typical attributes of plutonium from a nuclear weapon are:

- presence of plutonium $\left({ }^{239} \mathrm{Pu}\right)$

- isotopic composition of the plutonium is less than $10 \%{ }^{240} \mathrm{Pu}\left({ }^{240} \mathrm{Pu} /{ }^{239} \mathrm{Pu}\right.$ value to $\left.\pm 5 \%\right)$

- mass of the plutonium (over a threshold mass)

- plutonium age (separated before some date)

- plutonium in metal form rather than oxide form

- axial symmetry

Existing radiation-based measurement systems for determination of the attributes of plutonium listed above require techniques involving either 1) a high-resolution gamma-ray measurement, or 2) both neutron and high-resolution gamma-ray measurements. The methods used for measuring these attributes are still under development, but currently are:

- $\quad$ Presence of plutonium - Identification of specific and unique plutonium peaks in a high-resolution gamma-ray spectrum is used. Measurement of the $414-\mathrm{keV}$ peak with a low-resolution $\mathrm{NaI}(\mathrm{Tl})$ sensor along with neutrons is also considered adequate.

- Plutonium isotopics - The amplitude ratio of specific ${ }^{239} \mathrm{Pu}$ and ${ }^{240} \mathrm{Pu}$ peaks in a highresolution gamma-ray spectrum from a HPGe detector is required. A low-resolution $\mathrm{NaI}(\mathrm{Tl})$ sensor can not adequately resolve these peaks to determine the isotopics. The plutonium isotopic composition attribute cannot be determined solely from neutron measurements.

- $\quad$ Plutonium mass - Neutron-based systems are more useful in determining the plutonium mass from only the measured data without extra information regarding the sample. However, plutonium mass information can also be provided solely by the HPGe system 
for either known geometry or empirically modeled geometry, as demonstrated by the Minimum Mass Estimate (MME) analysis in the Trusted Radiation Attribute Demonstration System (TRADS).

- $\quad$ Plutonium age - A HPGe spectrum is required to determine the age attribute. Age is determined from decay schemes and specific peak amplitude ratios (e.g., ${ }^{241} \mathrm{Pu}$ and ${ }^{241}$ Am peaks).

- Plutonium form - The presence of metal versus plutonium compounds ("oxide") can be determined to some degree by high-resolution gamma-ray spectrometry, neutronenergy spectrometry, or an EM-coil measurement.

- Axial symmetry - Symmetry can be determined by either neutron or gamma technology. High-resolution gamma-ray spectrometry is not required; low-resolution or gross counting may be adequate.

The capability to measure multiple attributes has already been demonstrated using a HPGe detector with a neutron multiplicity counter (NMC) in the Fissile Material Transparency Technology Attribute Measurement System (FMTT-AMS) demonstration within a 60-minute measurement time. The TRADS system has demonstrated the ability to measure plutonium mass and the isotopic ratio with only a HPGe detector within a 10-minute measurement time. The measurement of the "oxide" attribute is an open problem. 


\section{Appendix B. Non-Nuclear Measurement Methods}

The following briefly discusses the various non-nuclear, low-intrusion measurement techniques, whether applied to an attribute measurement system or in a templating application.

\section{A. EM Coil Impedance or Other Electromagnetic Property ${ }^{8}$}

It is possible to measure the complex impedance of an external electromagnetic (EM) coil surrounding a canister containing a sample. This technique measures different mutual inductance values when different materials are placed within the coil. A simple physics analogy of this measurement is the change in inductance of a tunable radio coil when a core of magnetic material is inserted.

The EM-coil impedance measurement is made at several frequencies from about $50 \mathrm{~Hz}$ to $1000 \mathrm{~Hz}$. Above $1000 \mathrm{~Hz}$, the skin depth prevents adequate penetration of the canister walls. The AT400R canister to be used at FMSF at Mayak has walls that typically contain a total of about 2.5 centimeters of stainless steel. These walls can be adequately penetrated by frequencies up to about $3 \mathrm{kHz}$. This requires a method of subtracting or removing the component of the complex impedance due to the canister from the combined measurement to obtain the desired information about the canister contents. Removing the canister effects is challenging because the individual material effects are not linearly combined and the canister wall thickness is not well controlled.

The phase angle of the complex impedance (resistance and reactance) measures the phase difference between the voltage and current in the coil, which varies with frequency. The phase angle is indicative of the element when only a single material is present and several other variables are known. The amplitude of the complex impedance measures the amplitude of the induced eddy currents set up in the material. The current depends on the cross sectional area, the resistance of the material, and the magnetic permeability. Both the geometry of the material (shape and dimensions) and the orientation affect the amplitude of the complex impedance. When a hockey-puck-shaped sample shares a common symmetry axis of the EM-coil, more eddy currents are set up than when a puck or disk axis is perpendicular to the coil. When an electrically insulating material is inserted into the coil, no eddy currents are set up in the insulator and the contribution to the complex impedance amplitude is minimal. Thus, insulating materials like $\mathrm{PuO}_{2}$ and polyethylene moderator have no affect on the EM coil impedance.

A technique exists to remove a canister signature from the composite signature. If a sample is either a metal or an oxide, it is easy to distinguish between them. When an EM coil is placed over a canister containing metal, the regions without the metal exhibit lower complex impedance than the central region with the metal.

\footnotetext{
${ }^{8}$ Hockey
} 
If a canister were ferromagnetic (e.g., cold rolled steel) rather than austenitic (e.g., stainless steel), the skin depth of the electromagnetic radiation would be far less and the EM-coil technique would require more analysis to be useful. The EM-coil technique has been shown to work with ferromagnetic steel walls up to $0.2 \mathrm{~cm}$ thick and austenitic (stainless steel) walls up to $4.0 \mathrm{~cm}$ thick.

Another application for the EM-coil impedance measurement method is determining oxide layer thickness for known weights of plutonium metal. A simple calculation based on coil impedance measurements shows that if the only difference between two samples is diameter, the EM-coil impedance can resolve metal diameter to within 1 percent for diameters in the two to four $\mathrm{cm}$ range and much better for diameters above four $\mathrm{cm}$.

\section{B. Calorimetry and Heat Capacity ${ }^{9}$}

Calorimetry is a standard laboratory technique used to measure the heat released by a chemical or nuclear reaction source. For example, calorimetry is applied at the Hanford site to measure the mass of plutonium in a sample. Heat is released by the radioactive decay of plutonium and daughter americium radionuclides. The plutonium mass can be calculated from the temperature increase in the calorimeter after the sample has reached thermal equilibrium. The calculation of mass requires a measure of the heat released and the isotopic concentration of every radionuclide present in the sample. The isotopic concentration is generally recorded for each batch of identical samples based on either destructive analysis (mass spectroscopy) or nondestructive analysis (gamma-ray spectroscopy). Calorimetry generally requires a long measurement duration (several hours) before thermal equilibrium is reached. Calorimetry is more difficult to implement with samples in canisters such as an AT400R because of the high heat capacity and low heat conductivity of the massive polypropylene inserts and the thick stainless steel canister walls compared to the thin walled food-pack cans used for material storage at Hanford. The heat-bridge internal to the AT400R, critical to maintaining thermal control of stored plutonium at the FMSF Mayak, reduces the time required to achieve thermal equilibrium.

The measurement of the heat capacity of a sample can differentiate materials, especially metal from non-metal. However, this measurement would be difficult to implement with samples in canisters such as an AT400R because of the high heat capacity and low heat conductivity of stainless steel compared to the thin walled cans used for oxide material storage in the US. A concept system might consist of an enclosure that raises or lowers the environmental temperature, and then measures the time to reestablish equilibrium for the container and contents. It might be possible to extract sufficient information by monitoring the temperature change as a function of time for a shorter period.

\section{IR Imaging ${ }^{10}$}

\footnotetext{
${ }^{9}$ PANDA p. 617-656

${ }^{10}$ Batishko
} 
Infrared imaging measurements provide an accurate temperature profile of the exterior of a container. This technique can be applied to observing the presence of a persistent heat source (not a battery). Linked to knowledge of convective, conductive, and radiative heat transfer, IR imaging can provide a persistent power output measurement that is linked to mass. IR imaging systems produce an image of the heat as it arrives on the outside of a container, which is determined by the heat-bridge from the inside to the outside. IR imaging is a form of Calorimetry that views the canister in situ and uses the external temperature distribution when the canister is in thermal equilibrium with its environment. If the canister has been recently moved or the environmental temperature recently changed, the external temperature distribution may not relate to thermal equilibrium conditions.

In some limited cases, an IR image could provide some information about the source geometry. The image shape could be converted into a volume estimate, which can be combined with the mass measurement to obtain a density estimate. In the AT400R with thick stainless steel walls, the thermal image relates more to the geometry of the heat-bridge than to the plutonium sample, due to the poor heat conductivity of stainless steel.

\section{Weight Measurement or Density Determination ${ }^{11}$}

Weighing a canister can place a limit on the contents of a container and can provide an accurate comparison against variation over time. A typical canister such as an AT400R weighs much more than the plutonium sample contained within. The manufacturing tolerances on the canister wall thickness may mask variations in the plutonium sample within. If variations in the canister weights are larger than the weight of the plutonium, little is gained by this technique other than a specific item attribute that can be compared over time. Wall thickness variations have not been explored to our knowledge for a large sample of the AT-400R containers. Some confidence when containers are kept in secure storage might be obtained by sequentially tracking in time the gross mass of identified canisters, but it is potentially possible to replace the plutonium with other material to the accuracy of a weight measurement.

Special nuclear materials have high density, so a density determination can differentiate heavy metals from light metals and from oxide. Density might be determined by a variety of indirect techniques including weight measurement, x-ray attenuation for thin samples, gammaray-to-neutron ratio, acoustic techniques, etc. This concept has not been developed to any realizable practice.

\section{E. Inertial Measurement of Mass Properties ${ }^{12}$}

A measurement of the moments of inertia can place symmetry, density, mass, and shape constraints on a sample. The moment of inertia measures the mass weighted by the radius about the axis of rotation. The three independent moments of inertia about the center of mass could be

\footnotetext{
${ }^{11}$ LANL 1993

${ }^{12}$ ATWG Preliminary Report 1999
} 
determined by rotation of an item about three orthogonal axes. Depending on what is assumed regarding a canister and its contents, geometry parameters can be extracted from moment of inertia measurements. The moments of inertia might be used to correct the net weight of the plutonium sample for uncertainty in the canister mass. The thick walls of the AT400R dominate the moment of inertia about the center of mass because the massive walls are at a large radius. If the moments of inertia of the canister are accurately known, they can be subtracted out and the mass and radius of an internal sphere calculated. In principle, it is possible to determine the sample mass and density from the moments of inertia along with a modest geometrical model of the canister and contents with two adjustable parameters to reduce uncertainties due to loose manufacturing tolerances. Note that any density inference allows determination of the plutonium form as metallic or oxide.

Use of a moment-of-inertia technique in conjunction with weighing identified canisters makes it more difficult to simply replace the plutonium with an equal mass of some other material.

\section{F. Acoustic or Mechanical Resonance or Imaging ${ }^{13}$}

Mechanical resonance, produced by shaking, acoustics, or hitting, can provide a template for a sample. The tone of a tuning fork or of an organ pipe are examples of mechanical resonance. The response of a metal sample would be different than that from an oxide sample since properties such as rigidity and sound velocity are much different. Shape changes might also be noted for an oxide sample after mechanical shaking. Templating of a sample would allow comparisons over time. The support structure for a sample inside of a container could have a major impact on the feasibility of such techniques. Acoustic transmission or imaging similarly utilizes an acoustic source and detectors to determine system response to acoustic input.

A concept system would utilize a variable frequency sound source to map out the complex acoustic response of the container and contents, including any mechanical resonances. This acoustic map would be characteristic of the container and contents. The uniqueness of such a map would need to be demonstrated for a specific proposed system. The value of a resonance technique is the large signal increase in response to some specific input (e.g., frequency). However, the exploited resonance loses value if it is not unique to the desired canister contents. The response to acoustic stimulus would potentially be different for a container holding a metal sample versus one containing an oxide sample, since oxide might undergo a shape change under vibration or shaking.

Evaluation of this technique would be aided by specific examples of resonance systems. The vibrations experienced on a helicopter exhibit a resonance when passing through the transition between hovering and flight; however, many aspects of the design and load affect the speed and frequency. Vibration damping is often custom designed to be especially effective at natural vibration frequencies. Organ pipes have basic resonant frequencies depending on their geometry, but holes and inserts can affect both the frequency and harmonic content. The quality of

\footnotetext{
${ }^{13}$ Krautkramer 1990; LANL 1993
} 
organ music is not altered if more than one combination of holes and inserts produces the same results, but the ability to verify the cause of a result is lost without a one-to-one mapping.

\section{G. Chemical Sensing, Gas Chromatography, and Mass Spectrometry ${ }^{14}$}

Sensitive chemical detection methodologies can determine the presence of specific elements or compounds. All chemical sensing requires access to the unique compound being sought. Materials of interest include plutonium, uranium, or high explosive. Nuclear weapons are typically hermetically sealed, and plutonium in storage canisters similar to the AT400R is typically well contained. One does not expect detectable vapors to escape the hermetic seals and any surface contamination is more likely from the storage/dismantlement environment than the specific object. To be viable any chemical sensing technique must include a clear means of access to the materials of interest. Detection of external contamination could indicate a safety hazard situation.

There are various techniques for mass spectrometry including chromatographs, magnetic or electromagnetic systems, solid state devices, etc. Such chemical sensing techniques have limited applicability to special nuclear materials, but may be relevant to safety concerns or high explosives.

\section{H. Autoradiography ${ }^{15}$}

Autoradiography is an image produced by the intrinsic radiation emission (x-ray, gammaray, or neutron) of a sample and can produce a crude picture of an object, which yields geometric information. The source image can be used to measure the shape of the sample. The shape can be converted into a volume estimate, which can be combined with the mass (from a neutron or weight measurement) to obtain a density estimate. Similar concerns regarding the classification of an X-ray image apply, but the spatial resolution of the autoradiography image is often reduced due to the extended internal radiation source. The high spatial resolution of an X-ray is due to shadow shielding a relatively collimated beam from an external source. Autoradiography can take many forms. The common feature is not using an external radiation source to produce the image. This is a completely passive technique. This technique can be implemented in an electronics-free manner, which could make it more acceptable to a treaty partner.

Surrounding the canister with photographic film that has been sensitized to x-rays, gamma rays, or neutrons produces the simplest autoradiograph. This will produce an image analogous to a contact print of the radiation distribution at the canister surface due to the enclosed radiation source. The distance between the radiation source and the canister surface generally limits image resolution. Since the flux from a point source within the canister diminishes as $1 / \mathrm{r}^{2}$, the image of a centrally located point source would be a band with height about equal to the canister diameter. Since a typical canister diameter is large compared to a typical plutonium

\footnotetext{
${ }^{14}$ ATWG Preliminary Report 1999

${ }^{15}$ Miller
} 
source, any image will be very crude at best. In addition, the response of film to radiation is nonlinear. However, a more detailed image of variations in any shielding material surrounding a central point source is possible depending on proximity to the canister wall. For example, a small hole drilled through a massive shield surrounding a source would provide an image of more intense radiation varying with the hole diameter. The film can be replaced with other radiation sensitive materials such as optically stimulated luminescent material to improve sensitivity or enhance computerized readout, but the media does not improve the image resolution. Other media, such as stimulated phosphor plates, offer comparable resolution and a much better correlation between dose and image intensity. These plates have been developed for many clinical imaging applications, where their combination of good image quality, digitized image data, and lack of consumables has been a decisive advantage compared to film.

Some form of collimation in front of the sensitive material can be used to improve the image resolution. One example is to scan the canister with a collimated gamma-ray sensor. Another example is to add a honeycomb collimator in front of a photographic film or replacement material. These techniques have been developed for many clinical applications.

\section{I. $\underline{\text { X-Radiography }}{ }^{16}$}

X-rays of a canister can produce an image dependent upon the density of the enclosed material and can produce a geometric image of the enclosed object. The X-ray beam energy used can be varied to produce a more penetrating beam, which would provide information related to the density of the sample material. The thick walls of some storage canisters (e.g., AT400R) will require energetic X-rays to achieve adequate penetration for imaging. This X-ray technique is an active technique and is only considered for use to validate empty containers.

X-ray bombardment can also be used to determine the presence of specific elements. Each element has a K-edge at a unique energy. The mass attenuation coefficient of an element as a function of energy decreases with energy at low energies, but increases sharply at the Kedge and then continues to decrease with about the same slope. The K-edge is due to a resonance excitation of electrons in the atom by the incident X-rays. Specific elements might be identified by either noting the energy of the absorption change in a transmission beam or by noting the energy of X-rays emitted at right angles to the transmission beam as the K-shell is refilled. The width of the transmission resonance is typically dominated by the energy distribution of the incident beam. The width of the emission resonance is dominated by detector resolution. For example, the $\mathrm{K}$-edge is at $\mathrm{KP}_{2,3}=88.003 \mathrm{keV}$ for lead. These should be distinguishable with a high-resolution X-ray sensor.

\section{J. Neutron Interrogation}

Neutron interrogation is normally considered to be a nuclear technique, but is included here for completeness. Neutron interrogation is only considered in the context of empty or non-

\footnotetext{
${ }^{16}$ LANL 1993
} 
sensitive containers. Neutron interrogation has been discussed in the context of non-nuclear material component applications. Two neutron interrogation approaches are potentially useful.

In the first neutron interrogation approach, a neutron source is used to induce activity in a sample through induced fission, excitation, or absorption. The resulting x-rays, gamma rays, or neutrons can be observed through a variety of detection techniques.

Several implementations of neutron interrogation of nuclear materials have been demonstrated. The portable isotopic neutron spectrometer (PINS) was developed by INEEL for neutron interrogation of materials such as explosives and chemical warfare agents. ORNL developed the NMIS measurement system that consists of multiple plastic scintillators to look for neutron coincidences from a sample with (active) or without (passive) a time-tagged californium neutron source. PNNL and LLNL cooperatively attempted neutron-induced gamma-ray spectroscopy on nuclear materials in canisters. A ${ }^{252} \mathrm{Cf}$-neutron source (as used for NMIS) was placed near canisters and the gamma-ray spectra out to $12 \mathrm{MeV}$ were recorded. The spectra were analyzed for peaks due to induced fission products and neutron-induced gamma rays without success. A host of neutron-induced gamma-ray peaks due to neutron activation, prompt neutron capture, and neutron inelastic scattering in materials in the surrounding environment, in the HPGe sensor, and in stainless steel were found, but unique neutron-induced peaks related to materials of interest were not found. Peaks unique to fission products were also not found. Another such neutron interrogation system was developed by Beddingfield at LANL. ${ }^{17}$

Neutron scattering or thermalization times can be used to indicate the presence of a hydrogen-rich material such as HE. The neutron scattering method utilizes a time tagged neutron source to observe elastic scattered neutrons from hydrogen versus heavier materials. The technique uses an unmoderated ${ }^{3} \mathrm{He}$ detector to selectively detect neutrons moderated by hydrogen in the nearby environment. The ${ }^{252} \mathrm{Cf}$-neutron source is time tagged to avoid detection of neutrons directly from the source. The count rate in the acceptable time window is indicative of the amount of nearby hydrogen. Although presence of hydrogen does not uniquely correlate with $\mathrm{HE}$, the scheme is useful 1) in full-up weapons where HE is the primary source of hydrogen and 2) in showing a waste stream does not contain HE or other hydrogen sources. The primary advantage is a rapid measurement within a few seconds in contrast to the time required to acquire a $2223-\mathrm{keV}$ peak with a gamma-ray sensor. ${ }^{18}$

${ }^{17}$ Caffrey 1992, 1994; Mihalczo 1997 and Valentine 1999; Beddingfield 1998

${ }^{18}$ Craig 2000 


\section{Appendix C. Comparison of Nuclear and Non-Nuclear Measurement Methods}

Tables 3-7 provide a summary of material attributes of interest to arms control and the possible nuclear and non-nuclear methods for measurement of that attribute. The attributes were established largely based upon radiation measurement methodologies. The tables include attributes for plutonium, uranium, other fissionable materials, and high explosives. These techniques may or may not produce a signature unique to the indicated attribute.

Table 3: Plutonium Material Attributes of Interest to Arms Control

\begin{tabular}{|c|c|c|}
\hline Plutonium Attribute & Radiation Measurement & Alternate Technology \\
\hline Presence of Plutonium & $\begin{array}{l}\text { HPGe spectra - Several } \\
\text { characteristic gamma rays } \\
\text { from plutonium (unique } \\
\text { and not easily spoofed) } \\
\text { - } \quad \text { Neutron-induced gamma- } \\
\text { ray HPGe spectra (neutron } \\
\text { induced gamma rays are } \\
\text { very weak) } \\
\text { NaI(Tl) spectra - peaks } \\
\text { not resolved sufficiently } \\
\text { (requires neutron flux and } \\
414-k e V \text { gamma-ray peak) } \\
\text { Neutron counting or imag- } \\
\text { ing }\end{array}$ & 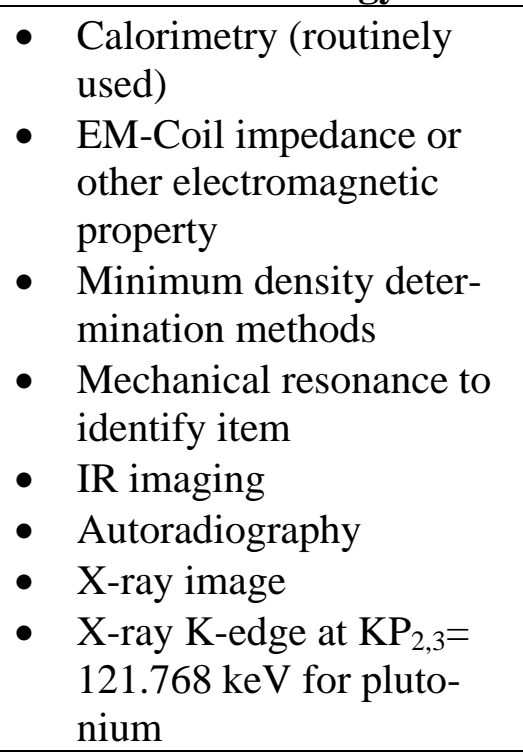 \\
\hline Absence of Plutonium & 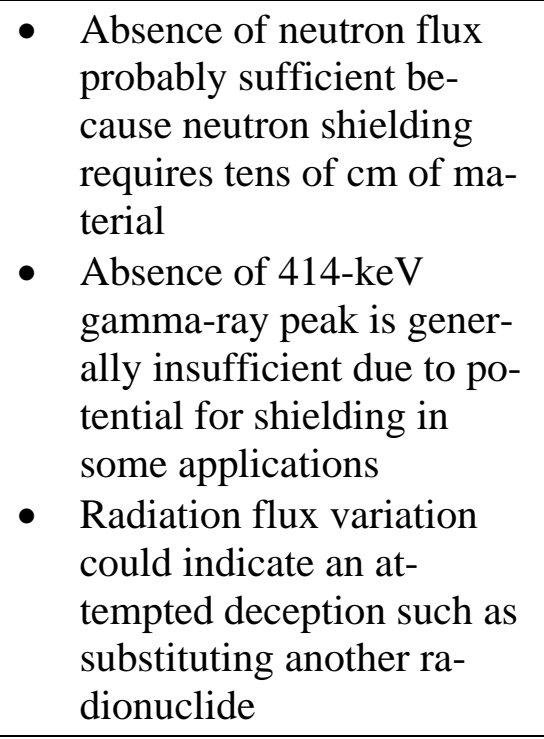 & 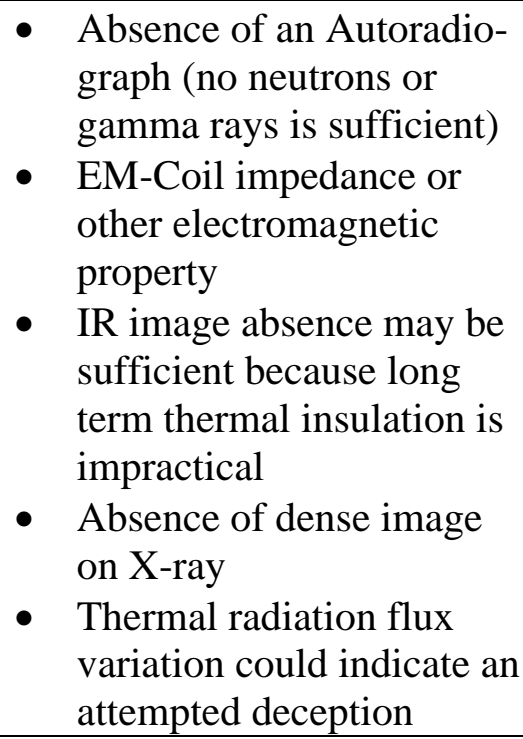 \\
\hline
\end{tabular}




\begin{tabular}{|c|c|c|}
\hline Plutonium Attribute & Radiation Measurement & Alternate Technology \\
\hline Mass of Plutonium & $\begin{array}{ll}\text { - } & \text { Minimum mass estimate } \\
\text { (MME) from gamma-ray } \\
\text { spectra } \\
\text { - } & \text { Singles neutron counting } \\
\text { - } & \text { Doubles neutron counting } \\
\text { - } & \text { Neutron multiplicity } \\
\text { measurement } \\
\text { - Neutron and gamma-ray } \\
\text { counting against a stan- } \\
\text { dard }\end{array}$ & $\begin{array}{l}\text { Simple weight measure- } \\
\text { ment (net wt problem) } \\
\text { - Calorimetry of thermal } \\
\text { source strength relates to } \\
\text { mass (routinely used) } \\
\text { - Moment of inertia meas- } \\
\text { urement under rotation or } \\
\text { shaking } \\
\text { - Heat capacity }\end{array}$ \\
\hline $\begin{array}{l}\text { Weapons-grade plutonium } \\
\text { from }{ }^{240} \mathrm{Pu}:{ }^{239} \mathrm{Pu} \text { isotopic ratio }\end{array}$ & $\begin{array}{l}\text { HPGe gamma-ray meas- } \\
\text { urement (use of two peaks } \\
\text { in the 600-670 keV region) } \\
\text { HPGe gamma-ray meas- } \\
\text { urements in low-energy } \\
\text { spectral regions (normally } \\
\text { used for MGA or FRAM } \\
\text { code) }\end{array}$ & $\begin{array}{l}\text { - Thermal signal indicative } \\
\text { of mass (Calorimetry con- } \\
\text { sistent with independent } \\
\text { mass measurement) }\end{array}$ \\
\hline Age of Plutonium & $\begin{array}{l}\text { - }{ }^{241} \mathrm{Am}:{ }^{241} \mathrm{Pu} \text { peak ratio in } \\
300-400 \mathrm{keV} \text { region (prob- } \\
\text { lem with attenuation in } \\
\text { steel canister and one peak } \\
\text { is minor component of an- } \\
\text { other peak) } \\
\text { - HPGe gamma-ray meas- } \\
\text { urements in low-energy } \\
\text { spectral regions (normally } \\
\text { used for MGA or FRAM } \\
\text { code) } \\
\text { Relative Peaks of all Pu } \\
\text { isotopes which decay at } \\
\text { different rates }\end{array}$ & $\begin{array}{l}\text { - Thermal signal indicative } \\
\text { of age with known mass } \\
\text { and isotopic ratio }\end{array}$ \\
\hline
\end{tabular}




\begin{tabular}{|c|c|c|}
\hline Plutonium Attribute & Radiation Measurement & Alternate Technology \\
\hline $\begin{array}{l}\text { Plutonium in metallic (not } \\
\text { oxide or other chemical) form }\end{array}$ & $\begin{array}{l}\text { Presence of the 871-keV } \\
\text { peak indicates non- } \\
\text { metallic (but not oxide) } \\
\text { Alpha-induced neutron } \\
\text { production - NMC } \alpha \text { - } \\
\text { value (problem with Be } \\
\text { and other low-Z impuri- } \\
\text { ties) } \\
\text { Gamma-ray peaks due to } \\
\text { alpha-induced neutron } \\
\text { production - 2438- and } \\
\text { 2788-keV peaks (need to } \\
\text { show sufficient signal ex- } \\
\text { ists) } \\
\text { NMC } \alpha \text {-value with low-Z } \\
\text { elements eliminated by ab- } \\
\text { sent HPGe peaks (e.g., } \\
\text { PuF } 3 \text { yields } 1275-k e V \\
\text { gamma) } \\
\text { Neutron/gamma ratio } \\
\text { related to density in known } \\
\text { geometry } \\
\text { NMC multiplication con- } \\
\text { sistent with metal rather } \\
\text { than oxide }\end{array}$ & 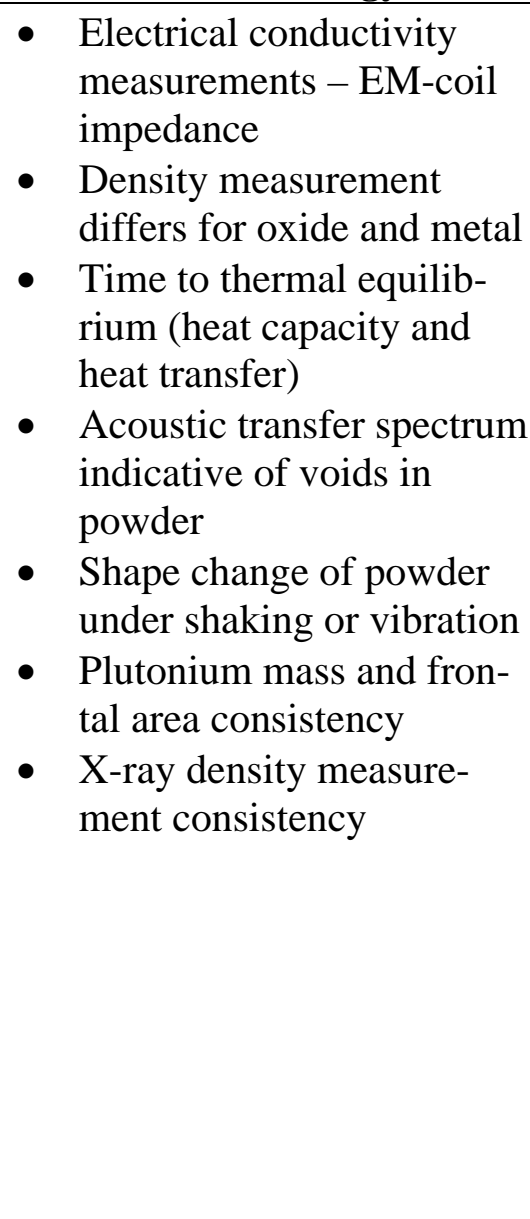 \\
\hline Axial symmetry of object & $\begin{array}{ll}\text { - } & \text { Neutron flux in multi- } \\
\text { neutron detector geometry } \\
\text { - } & \text { Neutron flux symmetry } \\
\text { under rotation } \\
\text { - } \\
\text { Gamma-ray symmetry } \\
\text { under rotation }\end{array}$ & $\begin{array}{ll}\text { - } & \text { Autoradiography } \\
\text { - } & \text { X-ray imaging } \\
\text { - } & \text { Acoustic imaging } \\
\text { - } & \text { Asymmetric impedance } \\
& \text { variation under rotation } \\
& \text { and translation }\end{array}$ \\
\hline
\end{tabular}


Table 4: Other Plutonium Material Attributes of Interest to Arms Control

\begin{tabular}{|c|c|c|}
\hline $\begin{array}{l}\text { Extended Plutonium } \\
\text { Attribute }\end{array}$ & Radiation Measurement & Alternate Technology \\
\hline Spherical symmetry of object & $\begin{array}{l}\text { - Extension of axial symme- } \\
\text { try (potentially intrusive) } \\
\text { - Cylindrical geometry of } \\
\text { canister limits utility }\end{array}$ & $\begin{array}{l}\text { - Extension of axial symme- } \\
\text { try }\end{array}$ \\
\hline $\begin{array}{l}\text { Plutonium object shape and } \\
\text { extent }\end{array}$ & $\begin{array}{ll}\text { - } & \text { Gamma-ray cameras } \\
\text { - } & \text { Gamma-ray scan to deter- } \\
\text { mine length \& diameter } \\
\text { - } & \text { Gamma-ray transmission } \\
\text { - } & \text { Potentially intrusive }\end{array}$ & $\begin{array}{l}\text { - } \text { Autoradiography } \\
\text { - X-ray image } \\
\text { - } \text { EM field } \\
\text { - } \text { Moment of inertia }\end{array}$ \\
\hline $\begin{array}{l}\text { Plutonium alloyed with gal- } \\
\text { lium }\end{array}$ & $\begin{array}{l}\text { Gallium neutron capture } \\
\text { peaks (not observable } \\
\text { within time constraints) }\end{array}$ & \\
\hline $\begin{array}{l}\text { Plutonium alloyed with other } \\
\text { materials }\end{array}$ & $\begin{array}{l}\text { Neutron spectrometry or } \\
\text { presence of specific } \\
\text { gamma rays can indicate } \\
\text { certain isotopes given ade- } \\
\text { quate measurement time }\end{array}$ & \\
\hline Plutonium phase $\alpha$ or $\delta$ & $\begin{array}{l}\text { Gamma/neutron ratio } \\
\text { effect due to surface to } \\
\text { volume effects } \\
\text { - NMC multiplication might } \\
\text { depend on } \alpha \text { or } \delta \text { phase }\end{array}$ & - Density difference \\
\hline Thickness of plutonium part & $\begin{array}{l}\text { - Self attenuation of set of } \\
\text { gamma rays viable }\end{array}$ & $\begin{array}{l}\text { - Skin depth properties may } \\
\text { be useful if can be cor- } \\
\text { rected for container effects } \\
\text { (e.g., EM-coil impedance) } \\
\text { - EM-coil can differentiate } \\
\text { solid versus hollow }\end{array}$ \\
\hline
\end{tabular}


Table 5: HEU Material Attributes of Interest to Arms Control

\begin{tabular}{|c|c|c|}
\hline HEU Attribute & Radiation Measurement & Alternate Technology \\
\hline Presence of Uranium & $\begin{array}{l}\text { - }{ }^{238} \mathrm{U} \text { daughter }{ }^{234 \mathrm{~m}} \mathrm{~Pa} \\
\text { gamma-ray peaks at } 1001 \\
\text { keV and several others are } \\
\text { unique in HPGe spectrum } \\
\text { - } 185-\mathrm{keV} \text { peak from }{ }^{235} \mathrm{U} \text { is } \\
\text { not unique to uranium and } \\
\text { easily shielded (e.g.. }{ }^{226} \mathrm{Ra} \\
\text { and }{ }^{67} \mathrm{Ga} \text { emit photons of } \\
\text { similar energy) } \\
\text { - Neutron-induced signature } \\
\text { - these are not easily ob- } \\
\text { served with HPGe } \\
\text { - NMIS }\end{array}$ & $\begin{array}{l}\text { EM-coil impedance meas- } \\
\text { ures complex impedance, } \\
\text { and phase is somewhat } \\
\text { unique to various materials } \\
\text { (not as definitive as a } \\
\text { resonance effect) } \\
\text { X-ray K-edge at } \mathrm{KP}_{2,3}= \\
115.58 \mathrm{keV} \text { for uranium }\end{array}$ \\
\hline Presence of HEU & $\begin{array}{l}\text { - } 2614-k e V \text { peak from }{ }^{232} \mathrm{U} \\
\text { daughter (problems with } \\
\text { background radiation \& } \\
\text { with }{ }^{232} \mathrm{U} \text { concentration in } \\
\text { all HEU) } \\
\text { - } 185-\mathrm{keV} \text { peak from }{ }^{235} \mathrm{U} \\
\text { (problem with penetration } \\
\text { \& present in natural and } \\
\text { depleted uranium) } \\
\text { - Neutron-induced signature } \\
\text { (not easily observed with } \\
\text { HPGe) } \\
\text { NMIS }\end{array}$ & $\begin{array}{l}\text { Accurate calorimetry } \\
\text { might be able to distin- } \\
\text { guish HEU from DU or } \\
\text { natural U if mass is pre- } \\
\text { cisely known and material } \\
\text { is homogenous }\end{array}$ \\
\hline Absence of HEU & $\begin{array}{l}\text { Absence of } 185-\mathrm{keV} \text { peak } \\
\text { from }{ }^{235} \mathrm{U} \text { is insufficient } \\
\text { because of easy shielding } \\
\text { potential } \\
\text { Absence of } 1001-\mathrm{keV} \text { and } \\
\text { other }{ }^{234 \mathrm{~m}} \mathrm{~Pa} \text { peaks is suffi- } \\
\text { cient because HEU always } \\
\text { includes penetrating }{ }^{234 \mathrm{~m}} \mathrm{~Pa} \\
\text { gamma-ray peaks unless } \\
\text { heavily shielded } \\
\text { - Absence of neutrons not } \\
\text { applicable because no sig- } \\
\text { nificant neutron emission }\end{array}$ & $\begin{array}{l}\text { Absence of dense image } \\
\text { on X-ray viable } \\
\text { Autoradiography clear (no } \\
\text { neutrons or gamma) is suf- } \\
\text { ficient } \\
\text { - Lack of IR image may be } \\
\text { sufficient because long } \\
\text { term thermal insulation } \\
\text { impractical (HEU is a very } \\
\text { small heat source com- } \\
\text { pared to } \mathrm{Pu} \text { ) }\end{array}$ \\
\hline HEU isotopics & $\begin{array}{l}\text { - } 185-\mathrm{keV} \text { peak from }{ }^{235} \mathrm{U}- \\
\text { problem with penetration } \\
\text { - } \\
\text { Neutron-induced signature }\end{array}$ & \\
\hline
\end{tabular}




\begin{tabular}{|c|c|c|}
\hline HEU Attribute & Radiation Measurement & Alternate Technology \\
\hline $\begin{array}{l}\text { Uranium alloyed with other } \\
\text { material }\end{array}$ & & $\begin{array}{l}\text { - Mass spectrometry if sam- } \\
\text { ple available }\end{array}$ \\
\hline $\begin{array}{l}\text { Uranium object shape and } \\
\text { extent (useful for reshaped } \\
\text { objects) }\end{array}$ & $\begin{array}{l}\text { - Gamma-ray cameras pos- } \\
\text { sible } \\
\text { - Gamma-ray scan to deter- } \\
\text { mine length \& diameter } \\
\text { useful } \\
\text { - Potentially intrusive }\end{array}$ & $\begin{array}{ll}\text { - } & \text { Autoradiography valuable } \\
\text { - } & \text { Gamma-ray image possible } \\
\text { - } & \text { Eddy currents possible } \\
\text { - } & \text { EM-coil impedance meas- } \\
& \text { urement }\end{array}$ \\
\hline Thickness of uranium part & $\begin{array}{l}\text { - Self attenuation of set of } \\
\text { gamma rays viable }\end{array}$ & $\begin{array}{l}\text { - Skin depth properties may } \\
\text { be useful }\end{array}$ \\
\hline
\end{tabular}

Table 6: Other Weapons Material Attributes of Interest to Arms Control

\begin{tabular}{|l|l|l|}
\hline Other Material Attribute & Radiation Measurement & Alternate Technology \\
\hline $\begin{array}{l}\text { Presence of fissionable mate- } \\
\text { rial other than HEU or Pu }\end{array}$ & $\begin{array}{l}\bullet \text { Gamma-ray spectral peaks } \\
\bullet \quad \text { Neutron detection }\end{array}$ & \\
\hline Presence of enriched ${ }^{6} \mathrm{Li}$ & & $\begin{array}{l}\text { Mass spectrometry if sam- } \\
\text { ple available } \\
\text { NMR if high magnetic } \\
\text { field can be applied }\end{array}$ \\
\hline Presence of enriched ${ }^{2} \mathrm{H}$ & & \multicolumn{2}{|l}{} \\
\hline
\end{tabular}


Table 7: High Explosives Material Attributes of Interest to Arms Control

\begin{tabular}{|c|c|c|}
\hline High Explosives Attribute & Radiation Measurement & Alternate Technology \\
\hline $\begin{array}{l}\text { Presence of high explosive } \\
\text { compounds }\end{array}$ & & $\begin{array}{l}\text { - Mass spectroscopy if sam- } \\
\text { ple available }\end{array}$ \\
\hline $\begin{array}{l}\text { Presence of nitrogen to indi- } \\
\text { cate high explosives }\end{array}$ & $\begin{array}{l}\text { Neutron induced gamma } \\
\text { rays } \\
\text { 10.8-MeV and other neu- } \\
\text { tron capture lines in nitro- } \\
\text { gen (not observable within } \\
\text { limited time with intrinsic } \\
\text { neutron flux of weapon) } \\
\text { - Any HPGe scheme must } \\
\text { avoid potential signal from } \\
\text { liquid nitrogen coolant }\end{array}$ & $\begin{array}{l}\text { - Mass spectroscopy if sam- } \\
\text { ple available }\end{array}$ \\
\hline $\begin{array}{l}\text { Presence of hydrogen to indi- } \\
\text { cate high explosives }\end{array}$ & $\begin{array}{l}\text { 2223-keV hydrogen neu- } \\
\text { tron capture peak } \\
\text { - Not used because it is } \\
\text { not considered suffi- } \\
\text { ciently unique to explo- } \\
\text { sives } \\
\text { - Useful signal observ- } \\
\text { able within limited time } \\
\text { with intrinsic neutron } \\
\text { flux of weapon } \\
\text { PNNL de-mining scheme } \\
\text { with neutron moderation } \\
\text { time measurement }\end{array}$ & $\begin{array}{l}\text { - Mass spectroscopy if sam- } \\
\text { ple available }\end{array}$ \\
\hline $\begin{array}{l}\text { Presence of chemical vapors } \\
\text { to indicate high explosives }\end{array}$ & & $\begin{array}{ll}\text { - } & \text { Dogs } \\
\text { - } & \text { Mass spectroscopy } \\
\text { - } & \text { Gas chromatography } \\
\text { - } & \text { Artificial noses (arrays of } \\
& \text { chemical sensors) }\end{array}$ \\
\hline
\end{tabular}


Appendix D. Some Properties of Plutonium

Table 8: Some Properties of Plutonium

\begin{tabular}{|l|l|l|l|l|l|}
\hline Property & Pu metal phase & $\mathbf{P u O}_{2}$ & Units & Comments & $\begin{array}{l}\text { Reference } \\
\text { Wick page }\end{array}$ \\
\hline Resistivity, $\rho$ & $146 \times 10^{-6} \alpha$ & $10^{14}$ & ohm-cm & At $0{ }^{\circ} \mathrm{C}$ & $40 \& 256$ \\
\hline $\begin{array}{l}\text { Paramagnetic } \\
\text { Susceptibility, } \chi_{\mathrm{g}}\end{array}$ & $2.23 \times 10^{-6}$ & & $\mathrm{emu} / \mathrm{g}$ & At $20^{\circ} \mathrm{C}$ & 41 \\
\hline $\begin{array}{l}\text { Molar Heat } \\
\text { Capacity, } C_{\mathrm{p}}\end{array}$ & 7.43 & & $\mathrm{Cal} /{ }^{\circ} \mathrm{K}$ & At $280^{\circ} \mathrm{K}$ & 38 \\
\hline Density & $\begin{array}{ll}19.86 \\
15.92\end{array} \quad \delta$ & 11.46 & $\mathrm{~g} / \mathrm{cm}^{3}$ & X-ray density & $34 \& 252$ \\
& $\delta$ & & & & \\
\hline
\end{tabular}

